\title{
Functional regulation of monocyte-derived dendritic cells by microRNAs
}

\author{
Yifan Zhan ${ }^{1,2}$, Li Wu ${ }^{3}$ \\ ${ }^{1}$ The Walter and Eliza Hall Institute of Medical Research, Parkville 3052, Australia \\ 2 Department of Medical Biology, University of Melbourne, Parkville 3010, Australia \\ ${ }^{3}$ Tsignhua University and Peking University Joint Center for Life Sciences and Tsinghua University School of Medicine, Beijing \\ 100084, China \\ $\triangle$ Correspondence: zhan@wehi.edu.au
}

Received May 7, 2012 Accepted June 15, 2012

\begin{abstract}
Dendritic cells (DCs) as a rare type of leukocytes play an important role in bridging the innate and adaptive immune system. A subset of DCs, monocyte-derived dendritic cells (moDCs), exists in very low numbers at steady state but become abundant in inflammatory states. These inflammation-associated DCs are potent producers of pro-inflammatory cytokines and potent inducers of $\mathrm{T}$ helper differentiation. They behave as a "double-edge" sword so that they not only mediate protective immunity but also immuno-pathology. It is still incompletely understood how their function is regulated. Emerging evidence indicates that microRNAs (miRNAs), as a new class of gene regulators, potently regulate the function of moDCs. Here we summarize recent progress in this area.
\end{abstract}

KEYWORDS dendritic cells, microRNA, function

\section{MONOCYTE-DERIVED DENDRITIC CELLS (moDCs) BECOME A MAJOR DC SUBSET IN INFLAMMATORY STATES}

Discovery of dendritic cells (DCs) in the early 1970s by the late Noble laureate Ralph Steinman (Steinman and Cohn, 1973) represents a great milestone of modern immunology. Continuous efforts over more than four decades have enhanced immensely our understanding of how DCs as professional antigen-presenting cells shape the adaptive immune response. As a whole, DCs can respond to various self and non-self antigens presented in environment and induce vastly different types of adaptive immune responses. To a large degree, DCs fulfil the vast different tasks by a division of labour among ever-growing members of the DC family (Shortman and Naik, 2007).

Mouse DCs can be grouped into lymphoid tissue-resident DCs, migratory DCs (also called non-lymphoid resident DC) and moDCs. Lymphoid tissue-resident DCs comprise three subsets of conventional DCs $\left(\mathrm{CD} 8^{+}, \mathrm{CD}^{+}\right.$and $\mathrm{CD} 4^{-} \mathrm{CD} 8^{-}$ DCs) and plasmacytoid DCs (pDCs). $C D 8^{+}$DCs are very proficient in producing IL-12 (Hochrein et al., 2001; Zhan et al., 2010), in engulfing cellular antigen (lyoda et al., 2002) and in presenting exogenously derived antigen into the $\mathrm{MHC}$ class I pathway (cross-presentation) (den Haan et al., 2000), and in the uptake of Listeria monocytogenes (Neuenhahn et al., 2006; Edelson et al., 2011; Zhan et al., 2011). pDCs are functionally potent IFN- $\alpha$-producers (Asselin-Paturel et al., 2001; Nakano et al., 2001; O'Keeffe et al., 2002). In lymph nodes but not in spleen, there are several additional types of migratory

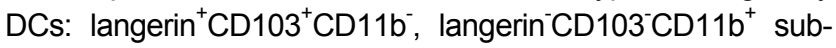
sets and Langerhans cells (langerin ${ }^{+}$CD103-CD11 ${ }^{+}$) (Poulin et al., 2007; Merad et al., 2008; King et al., 2010). Gut and

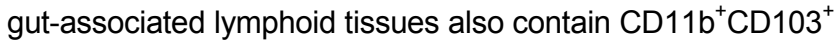
cells (Bogunovic et al., 2009; Varol et al., 2009). These migratory DC subsets also have quite unique functions (Kaplan et al., 2005; Bedoui et al., 2009; King et al., 2010; Lewis et al., 2011; Shklovskaya et al., 2011).

DCs represent a rare type of leukocyte in lymphoid tissues. Nevertheless, the above subsets of lymphoid tissue-resident DCs and migratory DCs are relatively abundant under the steady state. On the other hand, numbers of moDCs in lymphoid tissue are very low at steady state. However, in inflammatory states (in the presence of infection with bacteria, virus or parasites), moDCs becomes a major DC type. They differentiate from recruited monocytes after upregulating 
CD11C and MHC class II molecules (Serbina et al., 2003). The moDCs also express CCR2, Ly6c and Mac-3 that can distinguish them from resident $\mathrm{CD} 11 \mathrm{~b}^{+}\left(\mathrm{CD}^{+}\right.$and $\left.\mathrm{CD} 4^{-}\right) \mathrm{DCs}$. Recruitment of monocytes (moDC precursors) into inflammatory sites is largely dependent on CCR2 (Serbina and Pamer, 2006). Functionally, moDCs are major producers of pro-inflammatory cytokines (Serbina et al., 2003; Xu et al., 2007; Zhan et al., 2010), inducers of Th1 differentiation (Leon et al., 2007) and memory $T$ cell activation (Wakim et al., 2008), and antigen cross-presenting cells (Cheong et al., 2010). By exhibiting these potent functions, moDCs offer a protective immunity role as well as mediate immunopathology (Aldridge et al., 2009). In autoimmune inflammation, moDCs are likely to be the major mediators of pathology (Campbell et al., 2011).

MoDCs are one of the differentiation fates for monocytes as monocytes can also differentiate into many other types of tissue dendritic cells such as Langerhans cells and mucosal DCs (see a detailed review by Dominguez and Ardavin (2010)). Like other dendritic cells, moDCs seem also to contain subsets. Inflammatory moDCs that become abundant in acute infection are comprised of mainly $\mathrm{Ly} 6 \mathrm{c}^{+} \mathrm{CCR} 2^{+}$cells. Under some TLR stimulation, Ly6c ${ }^{-1 / 0 w}$ moDCs can be induced (Cheong et al., 2010).

GM-CSF has been commonly used to differentiate human and mouse DCs from monocytes and BM cells in vitro (Inaba et al., 1992; Reid et al., 1992; Santiago-Schwarz et al., 1993). With increasing knowledge of the presence of in vivo DC subsets, a question is which in vivo DC subset resembles the DCs generated in vitro in the presence of GM-CSF. By direct comparison of expression of surface markers and functions, it has been suggested that in vitro GM-CSF-differentiated DCs are the equivalents of in vivo moDCs that are capable of producing large quantities of TNF- $\alpha$ and inducible nitric oxide (NO) synthase emerging after infection (Xu et al., 2007). Despite that GM-CSF is a potent cytokine differentiating DCs from monocytes, how critical GM-CSF is for in vivo differentiation of moDCs is less clear. At least, in some mouse models, GM-CSF is believed to positively regulate the in vivo production of moDCs (Naik et al., 2006; Campbell et al., 2011). However, in response to acute infection like systemic infection with Listeria monocytogenes, recruitment /maturation of Ly6c ${ }^{+}$moDCs was not obviously hampered in the Gm-csf -/- mice (Zhan et al., 2012).

\section{REGULATION OF FUNCTIONAL SPECIALIZATION OF DC SUBSETS}

As division of labour among DC subsets is well-appreciated, it remains incompletely understood how this function diversification is achieved. In general, regulation of DC function may operate with several interplaying mechanisms.

Some diversification can be explained by differential expression of receptors and therefore differential responses to ligand stimulation. The most exemplary scenario is differential expression of pattern recognition receptors (PRR) by DC subsets. For example, $\mathrm{CD} 8^{+} \mathrm{DCs}$ but not $\mathrm{CD} 8^{-} \mathrm{DC}$ s express high levels of TLR3, CD8 ${ }^{-} \mathrm{DCs}$ and $\mathrm{pDCs}$ but not $\mathrm{CD} 8^{+} \mathrm{DC}$ express high levels of TLR7 (Edwards et al., 2003). Therefore, one would predict that these DC subsets would show differential responses to individual TLR ligands. However, not all $\mathrm{DC}$ functions can be explained by PRR expression. $\mathrm{CD} 8^{+}$, CD8 ${ }^{-} \mathrm{cDCs}$ as well as pDCs all express high levels of TLR9 but $\mathrm{CpG}$ stimulation still leads to differential cytokine production by these DC subsets (O'Keeffe et al., 2002; Zhan et al., 2010).

Apart from receptor expression, differential expression of transcription factors also plays a critical role. IRF-8, Btf3 and Id2 are critical for differentiation of $\mathrm{CD}^{+} \mathrm{CDCs}$ and certain $\mathrm{CD}_{103}{ }^{+}$tissue DCs (Aliberti et al., 2003; Edelson et al., 2010; Jackson, 2011; Sathe and $\mathrm{Wu}, 2011$ ), while IRF-4 on the other hand, is critical for differentiation of $\mathrm{CD}^{-} \mathrm{CDC}$ (Geissmann et al., 2010). PU.1 also exhibits differential effect on Fl3t-L-induced or GM-CSF induced DC differentiation (Carotta et al., 2010). Although these transcription factors control differentially the generation of DC subsets, it is less clear whether they have a direct role in regulating $D C$ function. A member of $\mathrm{NF \kappa B}$ family, c-Rel is thought to control IL-12p35 production by $\mathrm{CD}^{+}{ }^{+} \mathrm{cDCs}$ (Grumont et al., 2001). Despite the general importance of the NFKB family in cell activation including activation of DCs, how DC subsets utilize individual members of the $\mathrm{NF} \kappa \mathrm{B}$ family to control their function is less clear.

Regulation of gene expression in DCs does not necessarily involve a change in DNA sequence. For example, regulation of IL-12 production in DCs has been shown to be associated with an epigenetic mechanism of gene regulation by histone methylation (Wen et al., 2008). Within the past several years a new model of gene regulation has emerged that involves control of gene expression exerted by small non-coding RNAs (microRNAs, miRNAs). Such mechanism of gene regulation is increasingly recognized to play a critical role in regulating differentiation and function of DCs and DC subsets.

\section{MicroRNAs AS A NEW CLASS OF GENE REGULATORS}

MicroRNAs (miRNAs) belong to small regulatory non-coding RNAs to repress target transcripts post-transcriptionally. They are of $\sim 22$ nucleotides (nt) in their mature forms. Canonical miRNAs are initially transcribed as long primary transcripts (pri-miRNAs) bearing one or more miRNA hairpins. The pri-miRNAs are processed into a precursor miRNA (pre-miRNA) stem-loop of $\sim 60 \mathrm{nt}$ in length by the nuclear RNase III enzyme Drosha and its partner DiGeorge syndrome critical region gene 8 (DGCR8). Pre-miRNAs are then transported into the cytosol by Exportin-5 and further processed by the Dicer RNase III enzyme into mature, 22 nt-long 
double strand miRNAs. Multiple mechanisms have been described for miRNA-mediated gene silencing. In general, the RNA-induced silencing complex (RISC) containing the Argonaute (AGO) proteins act as core components. miRNAs typically contain several mismatches when paired with target mRNAs, causing translational repression and mRNA cleavage/degradation. Each miRNA is predicted to target multiple mRNAs while several miRNAs can also regulate one mRNA. Moreover, miRNA could also target transcription factors, adding much more complexity to their regulatory function (Xiao and Rajewsky, 2009).

miRNAs constitute one of the largest gene families with over 700 members in mouse and 1000 in humans. Within hematopoietic cells, miRNAs are differentially expressed by different lineages of hematopoietic cells (Chen et al., 2004). Within DC lineages, the miRNA expression pattern is also unique between DC subsets (Kuipers et al., 2010a). For the same type of DCs, expression of miRNAs can also change during activation (Ceppi et al., 2009; Sun et al., 2011).

Importance of miRNAs in control of differentiation and function of hematopoietic cells is clearly evident from studies that genetic disrupt critical enzymes important for the biosynthesis of miRNAs. By gene targeting, it has been shown that genetic deficiency of Drosha results in the loss of mature miRNAs (Chong et al., 2008). In hematopoietic cells, T cell-specific Drosha as well as Dicer conditional knockout mice both spontaneously develop lymphoproliferative multi-organ inflammatory disease and die within a few weeks of birth, again indicating that importance of the two enzymes in leukocyte differentiation and function (Chong et al., 2008). In DCs, lineage-specific $\left(\mathrm{CD} 11 \mathrm{c}^{+}\right)$deletion of Dicer caused reduction in langerhans cells without obvious perturbation of other subsets (Kuipers et al., 2010b). Lack of DC phenotypes is proposed to be due to the short life span of resident DCs and long half-life of miRNAs (Kuipers et al., 2010b), it could also be that deletion of Dicer in $\mathrm{CD}_{11 \mathrm{c}^{+}}$cells is too late to affect DC differentiation from CD11c precursors. Nevertheless, in vitro manipulation of miRNA expression in DC precursors can change development fate of normal DCs (Kuipers et al., 2010a). We also found that blocking biosynthesis of miRNAs in DC precursors with inducible deletion of Drosha perturbed DC differentiation in vitro and in vivo (YZ, unpublished data). Even removal of an individual miRNA profoundly perturbs development and function of immune cells including DCs (Rodriguez et al., 2007; Xiao et al., 2007). Taken together, miRNAs likely play some roles in regulating DC development (Turner et al., 2011). As DC homeostasis is controlled by cell survival/death, proliferation, migration, maturation as well as bona fide differentiation, how miRNAs contribute to DC homeostasis is yet to be unravelled.

Thorough and systemic analyses of expression of miRNAs by DCs and DC subsets, particularly DC subsets present in vivo, have not been reported. Individual miRNAs are therefore selected for functional evaluation based on limited expression data. Most of the current information available on the influence of miRNAs on DCs is from in vitro studies with GM-CSF differentiated DCs. We believe that these studies collectively provide a lead as to how miRNAs might regulate $\mathrm{DC}$ function and ultimately immune response to self and non-self antigens. In the following sessions we summarize the progress made recently in the field, particularly the studies on the roles of miRNAs in several aspects of moDC function.

\section{miRNAs REGULATE CYTOKINE PRODUCTION BY moDCs}

Although all DCs are capable of producing cytokines in response to TLR and non-TLR stimulation, moDCs are particularly potent producers of pro-inflammatory cytokines (Xu et al., 2007). When different DC subsets were isolated from Listeria monocytogene-infected mice, moDCs were the dominant $D C$ type to produce many pro-inflammatory cytokines (YZ, unpublished data). These cytokines critically shape $T$ cell differentiation into different lineages with unique functions. For example, IL-1, IL-6 and IL-23 are critical for induction/maintenance of a Th17 response (Stockinger and Veldhoen, 2007) while IL-12 is critical for induction of a Th1 response (Hsieh et al., 1993). Currently, how cytokine production by moDCs is regulated and how these will shape the adaptive immune response is still incompletely understood. Evidence that we have summarised below provides how miRNAs are involved in the regulation of cytokine production by moDCs. As individual miRNAs can have effect on multiple cytokines (as well as non-cytokine targets) and an individual cytokine can be subjected to positive and negative regulation by multiple miRNAs, here we have centred on the effect of different miRNAs on one particular cytokine.

\section{IL-1}

When human moDCs were stimulated with LPS, miR155 among several other miRNAs was highly up-regulated (Ceppi et al., 2009). Silencing miR-155 resulted in enhanced gene activation related to IL-1 production. Other up-regulated inflammatory cytokines that were associated with miR-155 silence included IL-6, TNF- $\alpha$ and IL-23 (Ceppi et al., 2009). The data suggest that miR-155 negatively regulates production of inflammatory cytokines. In search of the direct targets of miR-155, TAB2, an adaptor in TLR/IL-1 signaling cascade, was identified as a direct target (Ceppi et al., 2009).

\section{IL-6}

miR-155 acts as a negative regulator of production of IL-1 also regulates IL-6 production by human moDCs during LPS-stimulation (Ceppi et al., 2009). However, two subse- 
quent studies showed that miR-155 could also act as a positive regulator for production of several pro-inflammatory cytokines including IL-6, IL-23, IL-12 and TNF- $\alpha$ by LPS-stimulated in vitro derived mouse moDCs (O'Connell et al., 2010; Dunand-Sauthier et al., 2011). The modulation of cytokine production by miR-155 is explained by miR-155 targeting negative regulators of signalling: SOCS1 and SHIP1 (O'Connell et al., 2009; Lu, 2009). However, whether moDCs utilize miR-155 to target these negative regulators has not been examined. Apart from different sources of moDCs (human vs mouse), it remains to reconcile the contradictory findings regarding the role of miR-155 in regulating the production of proinflammatory cytokines by moDCs.

miR-142-3p was also identified as a key negative regulator of IL-6 (Sun et al., 2011). Differing from miR-155 that is strongly up-regulated after LPS stimulation, miR-142-3p is constitutively and highly expressed in resting moDCs but down-regulated after LPS stimulation (Sun et al., 2011). Also differing from miR-155 which targets upstream signaling of cytokine induction, miR-142-3p directly targets IL-6 mRNA and thus specifically affects IL-6 expression (Sun et al., 2011). In addition to the above two miRNAs that modulate IL-6 production by LPS-stimulated moDCs, miR-148/152 were also found to suppress IL-6 production by in vitro-derived moDCs via targeting calcium/calmodulin-dependent protein kinase II (Liu et al., 2010).

\section{IL-10}

As an anti-inflammatory cytokine, IL-10 is also subjected to regulation by miRNA (Sharma et al., 2009). In human Jurkat cell line, mIR-106a has been demonstrated to regulate IL-10 expression (Sharma et al., 2009). In macrophages, miR-466I (Ma et al., 2010) and miR-98 (Liu et al., 2011) are also implicated in regulation of IL-10. A recent study showed that mouse and human moDCs that were tranfected with miR-23b had increased IL-10 production when they were pulsed with ovalbumin (OVA) (Zheng et al., 2012). It is not clear from the study whether/how OVA or potentially contaminants including LPS actually stimulates moDCs. The study suggests that miR-23b causes inhibition of Notch1 and NFKB (Zheng et al., 2012).

\section{IL-12}

Several miRNAs had been reported to modulate IL-12 production. miR-21 was initially identified to inhibit IL-12p35 in a reporter system (Lu et al., 2009b). Furthermore, mutating miR-21 binding sites in IL-12p35 3'-untranslated region abrogated miR-21-mediated repression. Thus, IL-12p35 is likely the direct target of miR-21 (Lu et al., 2009b). These researchers further generated miR-21 deficient mice. Compared to wild type mice, in vitro derived moDCs from these mutant mice had enhanced production of IL-12 but not sev- eral other cytokines (including TNF- $\alpha$, IL-6 and IL-23) when they were stimulated with LPS (with or without IFN- $\gamma$ ) (Lu et al., 2011b). In vivo, miR-21 deficient mice also generated a stronger antigen-specific Th1 response, although which DCs contributed to Th polarization in vivo was not clear.

Another miRNA, miR-10a, also directly targets the IL-12 gene (Xue et al., 2011). Unlike miR-21, miR-10a negatively regulates IL-12/IL-23p40. Ectopic expression in moDCs suppressed both production of IL-12 and IL-23 (Xue et al., 2011). Expression of miR-10a in moDCs was down-regulated by TLR stimulation. The down-regulation perhaps allows production of IL-12 and IL-23. The study also showed that miR-10a expression is high in mucosal innate cells and expression was inhibited by intestinal microbiota (Xue et al., 2011). However, given the complex composition of mucosal DCs, which DC subset(s) expressing miR-10a was not indentified.

Compared to miR-21 and miR-10a that directly target IL-12 genes, some other miRNAs target signalling components that will cast effects on multiple targets. For example, miR-155 enhanced production of IL-12 by moDCs (O'Connell et al., 2010); miR-148/152 suppressed IL-12 production in addition to inhibition of IL-6 production (Liu et al., 2010); miR-23b decreased production of IL-12 while increasing IL-10 production (Zheng et al., 2012). As introduced above, miR-155 has been found as a positive regulator of IL-12 production by moDCs (O'Connell et al., 2010).

\section{TNF- $\alpha$}

Although a major task for DCs is to deal with pathogens/microbes, they also respond to self-antigens. Oxidized low-density lipoproteins (oxLDLs) are the risk factor for atherosclerosis and can stimulate a pro-inflammatory response (Chen et al., 2011b). In this context, it is interesting to note that oxLDLs increased the expression of miR-29a in human moDCs (Chen et al., 2011b). Manipulation of miR-29a expression established that miR-29a is a negative regulator of TNF- $\alpha$ by oxLDLs-stimulated moDCs (Chen et al., 2011b). Lipoprotein lipase was identified as a direct target of miR-29a. It remains to be tested whether miR-29a also regulates TNF- $\alpha$ in response to environmental antigens. miRNAs that impact on TNF- $\alpha$ production also include miR-155 (O'Connell et al., 2010) and miR-148/152 (Liu et al., 2010).

Although data generated in recent years show that several miRNAs critically regulate the cytokine production by moDCs (mainly from in vitro derived moDCs under GM-CSF) (Table 1 ), our understanding on the regulation is still very limited. How miRNAs regulate function of moDCs in vivo has not been examined. Particularly, there is lack of evidence that miRNAs are involved in immunity and immunopathology by regulating the production of cytokine by moDCs. Even for those miRNAs that are important in regulating disease process (O'Connell et al., 2010), delineation of the in vivo impact 
of a particular miRNA on different leukocytes remains a challenging task. Furthermore, given that the same miRNA had been shown to have contrast influence on the same lineage of leukocytes (Ceppi et al., 2009; O'Connell et al., 2010), validation and clarification of current findings in different settings is required before they can serve as the targets for harnessing immune response.

\section{miRNAs REGULATE MATURATION AND ANTIGEN PRESENTATION BY MODCs}

Apart from production of cytokines, moDCs also fulfill the role of antigen presentation. Antigen presentation by DCs is critically related to expression of MHC molecules and costimulatory molecules. Evidence presented below illustrates that miRNAs can also impact on maturation of moDCs (Fig. 1) and antigen presentation.

\section{Maturation from monocytes into moDCs}

Maturation of moDCs from human monocytes is accompanied with upregulation of DC-SIGN and downregulation of CD14. Based on DC-SIGN/CD14 expression ratios, miR-21, miR-34a, and their cognate targets WNT1 and JAG1 were found to negatively influence moDC differentiation (Hashimi et al., 2009, Cekaite, 2010). Similarly, inhibition of miR-511 and miR-99b resulted in reduced DC-SIGN levels (Tserel et al., 2011). As being a versatile miRNA, miR-155 is also positively involved in maturation of mouse moDCs (Dunand-Sauthier et al., 2011; Lu et al., 2011a). Transcription factor c-Fos as a target of miR-155 was negatively for moDC maturation (Dunand-Sauthier et al., 2011). Similarly for what was described for regulation of IL- 6 by miR-155 (Ceppi et al., 2009; O'Connell et al., 2010; Dunand-Sauthier et al., 2011), a positive role for miR-155 in mouse moDC maturation is con- trasted by a reported negative role of miR-155 for maturation of human moDC, at least based on DC-Sign expression (Martinez-Nunez et al., 2009). Maturation from monocytes into moDCs was also found to be correlated with decreased miR-211 (Lu et al., 2011a). Maturation of human CD14 ${ }^{+}$ moDCs was also found recently to be inhibited by miR-146a (Du et al., 2012).

\section{Costimulatory molecules}

LPS and other TLR ligands could induce up-regulation of cell-surface expression of $\mathrm{MHCll}$ (I-Ab) and costimulatory molecules (CD80, CD86 and CD40). The up-regulation was attenuated in in vitro-derived moDCs from miR-155-/- mice, leading to reduced antigen presentation and IL-2 production by $T$ cells (Dunand-Sauthier et al., 2011). Similar to miR-155, low expression of let-7i reduced CD80 and CD86 expression by LPS-stimulated moDCs and SOCS1 acts as a target of let-7i (Zhang et al., 2011). moDCs with low let-7i expression stimulated low proliferative T-cell response but favored expansion of regulatory T cells (Zhang et al., 2011).

At some circumstances, DCs express CD40L and costimulate $\mathrm{CD}^{+} \mathrm{T}$ cells via interacting with $\mathrm{CD} 40$ on $\mathrm{T}$ cells (Johnson et al., 2009). Interestingly, miR-146a was found to repress CD40L on human moDCs (Chen et al., 2011a). Since only certain but not all TLR ligands can strongly stimulate CD40L expression on DCs, it would be interesting to test whether CD146a can be induced preferentially by different TLR ligands.

\section{miRNAs REGULATE EFFECTOR FUNCTION BY moDCs}

moDCs are best-known for their production of pro-inflammatory cytokines and ability to induce $\mathrm{T}$ cell differentiation.

Table 1 miRNAs regulate production of pro-inflammatory cytokines by moDC

\begin{tabular}{lllll}
\hline Affected cytokines & miRNAs & Predicted/identified targets & Outcome & References \\
\hline IL-1 & miR-155 & TAB2 & Negative & Ceppi et al., 2009 \\
IL-6 & miR-142-3p & IL-6 & Negative & Sun et al., 2011 \\
& miR-148/152 & Calcium/calmodulin-dependent protein kinase Ila & Negative & Liu et al., 2010 \\
& miR-155 & TAB2 & Negative & Ceppi et al., 2009 \\
& miR-155 & SOCS1 and SHIP1 & Positive & O'Connell et al., 2010; Dunand- \\
& miR-23b & Notch1 and NFKB & Positive & Zheng et al., 2012 \\
IL-10 & miR-10a & IL-12p40 & Negative & Xue et al., 2011 \\
& miR-21 & IL-12p35 & Negative & Lu et al., 2009; Lu et al., 2011b \\
& miR-23b & Notch1 and NFKB & Negative & Zheng et al., 2012 \\
IL-12 & miR-148/152 & Calcium/calmodulin-dependent protein kinase Ila & Negative & Liu et al., 2010 \\
& miR-155 & SOCS1 and SHIP1 & Positive & O'Connell et al., 2010 \\
& miR-29a & & Negative & Chen et al., 2011b \\
& miR-155 & SOCS1 and SHIP1 & Positive & O'Connell et al., 2010 \\
& miR-148/152 & Calcium/calmodulin-dependent protein kinase Ila & Negaitve & Liu et al., 2010 \\
\hline
\end{tabular}




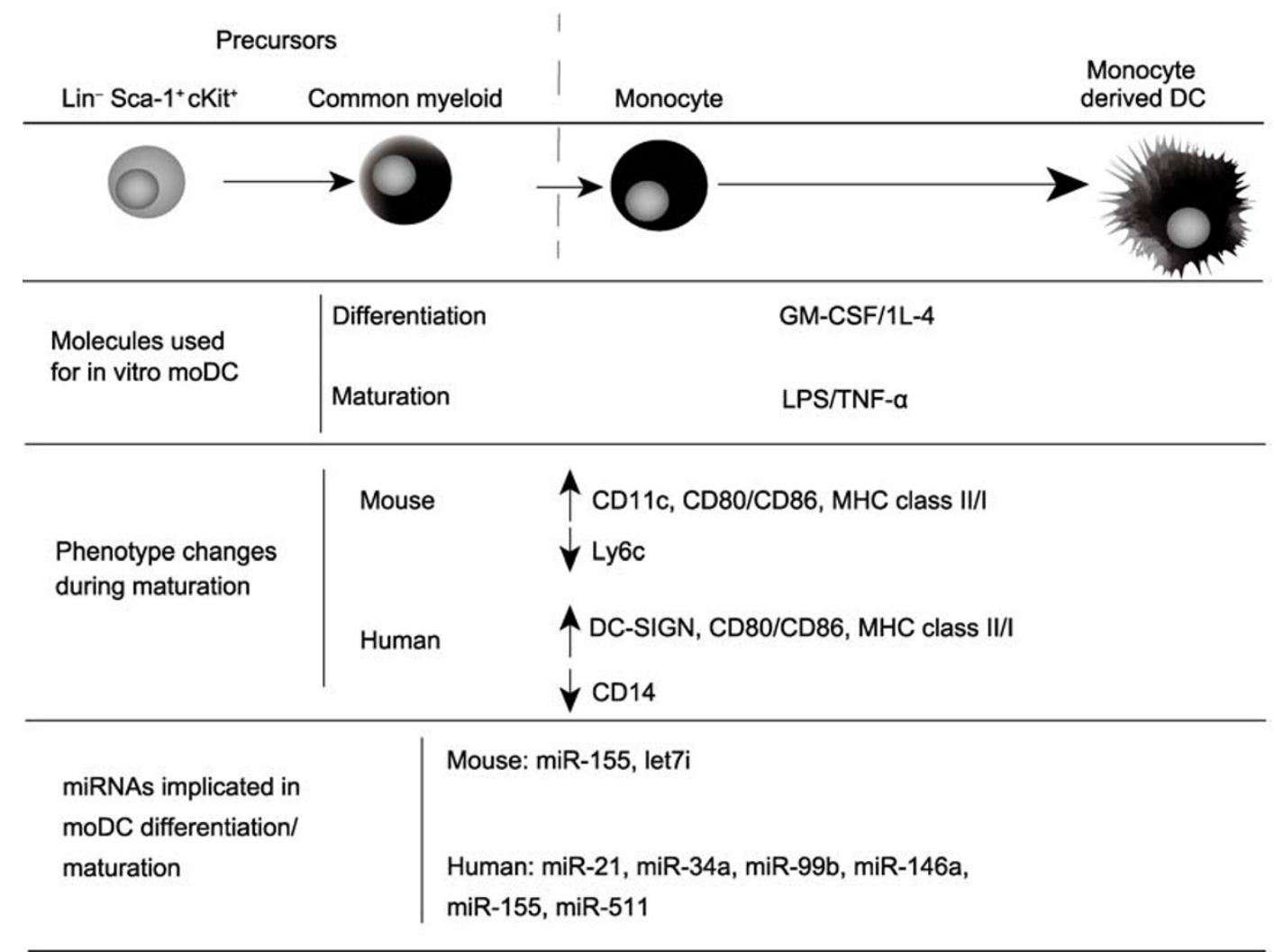

NB. Requirement for in vivo moDC differentiation/maturation has not been thoroughly examined. GM-CSF deficiency does not grossly affect infection-induced moDC maturation. Influence of miRNA on moDC function (cytokine production) is summarized in Table 1. Notably, certain miRNAs can influence both DC maturation and function.

Figure 1. Regulation of in vitro moDC differentiation/maturation by miRNAs.

However, they can also acts as effector cells like other myeloid cells. It is noted that certain effector functions are also subjected to regulation by miRNAs.

C-type lectin DC-SIGN can mediate binding of certain viral and fungal pathogens (Geijtenbeek et al., 2000; Lanoue et al., 2004). During LPS-mediated moDC maturation, miR-155 is up-regulated. In cell line with over-expressed miR-155, expression levels of transcription factor PU.1 and DC-SIGN was reduced (Martinez-Nunez et al., 2009). Suppression of miR-155 in moDCs increased DC-SIGN expression and improved the binding of HIV protein gp-120 and Candida albicans (Martinez-Nunez et al., 2009). Similarly, miR-155 has been found to negatively regulate lipid uptake by human moDCs (Chen et al., 2011c). As miR-155 seems to play a negative role in binding/uptake of antigens, miR-146a in human monocytic cell line showed to increase phagocytosis of Escherichia coli (Pauley et al., 2011).

\section{miRNAs AFFECT DIFFERENTIATION AND FUNCITON OF OTHER DCs}

The main body of current research on the role of miRNAs in regulating $D C$ differentiation and function was with in vitro GM-CSF differentiated DCs. However, several studies have investigated DCs other than moDCs.

Langerhans cells (LCs) are another type of DC that differentiate from monocytes. Relative to monocytes, LCs constitutively express high level of miR-146a (Jurkin et al., 2010). High miR-146a expression is induced by the transcription factor PU.1 in response to TGF- $\beta 1$ (Jurkin et al., 2010). However, forced expression of miR-146a in monocytes does not influence cell differentiation. It remains to be tested whether prevention of miR-146a upregulation during LC differentiation can alter cell fate. At least in mice deficient in miRNA biogenesis by targeting Dicer (Kuipers et al., 2010b) and Drosha in DC lineages (YZ, unpublished), the pool of LCs was severely diminished. Despite the fact that forced expression of miR-146a does not alter developmental fate, it does reduce TLR2-dependent NF $\kappa B$ signaling (Jurkin et al., 2010). Conversely, knockdown of miR-146a caused an increase in NFKB signaling (Jurkin et al., 2010). Thus the authors propose that high constitutive miR-146a levels by LCs make them less susceptible to inappropriate activation by commensal bacteria at the body surfaces. 
pDCs are specialized at production of IFN- $\alpha$ (AsselinPaturel et al., 2001; Nakano et al., 2001) and express high levels of TLR7 and TLR9 (Edwards et al., 2003). Study with human $\mathrm{pDCs}$ has revealed a fine-balanced role for miR-155 in regulating TLR7-stimulated IFN- $\alpha$ production (Zhou et al., 2010). Although TLR7 induced up-regulation of both miR-155* and miR-155 through the JNK pathway in pDCs, miR155* induced in the early phase of pDC activation enhanced IFN- $\alpha$ production by suppressing IRAKM, whereas miR-155 upregulated during the later time inhibited their expression by targeting TAB2 (Zhou et al., 2010). Thus, these two miRNAs cooperatively regulated the production of type-I IFN by human $\mathrm{pDCs}$.

\section{NON-CELL INTRINSIC miRNAs CONTRIBUTE TO REGULATE DC FUNCTION}

In the above sections, we discussed how miRNAs expressed by DCs participate in the regulation of differentiation and function of DCs. However, miRNAs can also be secreted to exhibit influence on surrounding cells (Valadi et al., 2007). Here we summarize a few examples of such non-cell intrinsic functions of secreted miRNAs in the context of DC function.

The first scenario is transfer of miRNA-containing small vesicles (exosomes) from non-DCs to DCs. It has been reported that EBV-transformed lymphoblastoid B cells (LCL) secrete exosomes that contain EBV-miRNAs. The EBVmiRNA containing exosomes are actively internalized by human moDCs. The EBV-miRNA can then suppress the expression of an EBV-targeted gene, chemokine CXCL11, which binds CXCR3 in moDCs (Pegtel et al., 2010).

The second scenario is transfer of miRNA-containing exosome between DCs (Montecalvo et al., 2012). In this very recent study, moDCs were found to release miRNA-containing exosomes with maturation-dependent contents. The study also revealed that spontaneous transfer of exosome between DCs occurs in up to $15 \%$ of recipient moDCs. Transfer of exosomes between moDCs is an active process since transfer was abrogated in the absence of calcium signalling (Montecalvo et al., 2012). The functional consequence of transfer of miRNA-containing exosomes between DCs remains to be investigated.

The third scenario is transfer of miRNA-containing exosome from DCs to non DCs. In the aforementioned study (Montecalvo et al., 2012), miRNA-containing exosome from moDCs can also be transferred into activated $\mathrm{CD} 4^{+} \mathrm{T}$ cells. In an early study, monocyte-derived miRNA-containing exosome can be transferred into cultured human microvascular endotheliel cells to regulate c-Myb expression and endothelial cell migration (Zhang et al., 2010).

\section{CONCLUDING REMARK}

Rapid progress has been made in recent years in our under- standing the role of miRNAs in regulating differentiation and function of DCs. These studies have helped us to better understand the biological significance of these miRNAs. However, notably, most of the current available evidence is derived from in vitro studies with GM-CSF-differentiated DCs, the equivalents of moDCs that become abundant during inflammation/infection (Xu et al., 2007). It remains to be tested whether these findings from in vitro studies can be applied to in vivo setting when very dynamic interaction between multiple types of immune cells and multiple components of microbes occur. Furthermore, complex DC networks consist of many types of $D C$ subsets with shared and unique functions. It remains largely unknown whether/how miRNAs regulate the function of different DC subsets. Further progress in our understanding of the regulatory role of miRNAs may aid to harness immune responses to maximize beneficial immunity and minimize detrimental immunopathology.

\section{ACKNOWLEDGEMENTS}

We thank Jamie Brady for critical reading of the manuscript. This work was supported by National Health and Medical Research Council of Australia (NH \& MRC) program and project grants (Nos. 575543, 637324 and 1007703), NHMRC Independent Research Institutes Infrastructure Support Scheme grant (No. 361646), and Victorian State Government Operational Infrastructure Support and the Australian Government. LW is supported by a grant from Tsinghua-Yu Yuan Foundation (No. 20200584) and by a Research Grant from Tsinghua University (No. 20111080963).

\section{ABBREVIATIONS}

AGO, Argonaute; DC, dendritic cells; LC, Langerhans cells; LCL, lymphoblastoid B cells; miRNAs, micro-RNA; moDC, monocyte-derived dendritic cell; NO, nitric oxide; oxLDL, oxidized low-density lipoprotein; OVA, ovalbumin; PDC, plasmacytoid DC; PRR, pattern recognition receptor; RISC, RNA-induced silencing complex; TLR, Toll-like receptor

\section{REFERENCES}

Aldridge, J.R., Jr., Moseley, C.E., Boltz, D.A., Negovetich, N.J., Reynolds, C., Franks, J., Brown, S.A., Doherty, P.C., Webster, R.G., and Thomas, P.G. (2009). TNF/iNOS-producing dendritic cells are the necessary evil of lethal influenza virus infection. Proc Natl Acad Sci U S A 106, 5306-5311.

Aliberti, J., Schulz, O., Pennington, D.J., Tsujimura, H., Reis e Sousa, C., Ozato, K., and Sher, A. (2003). Essential role for ICSBP in the in vivo development of murine CD8alpha + dendritic cells. Blood 101, 305-310.

Asselin-Paturel, C., Boonstra, A., Dalod, M., Durand, I., Yessaad, N., Dezutter-Dambuyant, C., Vicari, A., O'Garra, A., Biron, C., Briere, F., et al. (2001). Mouse type I IFN-producing cells are immature APCs with plasmacytoid morphology. Nat Immunol 2, 1144-1150.

Bedoui, S., Whitney, P.G., Waithman, J., Eidsmo, L., Wakim, L., 
Caminschi, I., Allan, R.S., Wojtasiak, M., Shortman, K., Carbone, F.R., et al. (2009). Cross-presentation of viral and self antigens by skin-derived CD103+ dendritic cells. Nat Immunol 10, 488-495.

Bogunovic, M., Ginhoux, F., Helft, J., Shang, L., Hashimoto, D., Greter, M., Liu, K., Jakubzick, C., Ingersoll, M.A., Leboeuf, M., et al. (2009). Origin of the lamina propria dendritic cell network. Immunity 31, 513-525.

Campbell, I.K., van Nieuwenhuijze, A., Segura, E., O'Donnell, K., Coghill, E., Hommel, M., Gerondakis, S., Villadangos, J.A., and Wicks, I.P. (2011). Differentiation of inflammatory dendritic cells is mediated by NF-\{kappa\}B1-dependent GM-CSF production in CD4 T cells. J Immunol 186, 5468-5477.

Carotta, S., Dakic, A., D'Amico, A., Pang, S.H., Greig, K.T., Nutt, S.L., and Wu, L. (2010). The transcription factor PU.1 controls dendritic cell development and Flt3 cytokine receptor expression in a dose-dependent manner. Immunity 32, 628-641.

Cekaite, L., Clancy, T., and Sioud, M. (2010). Increased miR-21 expression during human monocyte differentiation into DCs. Front Biosci (Elite Ed) 2, 818-828.

Ceppi, M., Pereira, P.M., Dunand-Sauthier, I., Barras, E., Reith, W., Santos, M.A., and Pierre, P. (2009). MicroRNA-155 modulates the interleukin-1 signaling pathway in activated human monocytederived dendritic cells. Proc Natl Acad Sci U S A 106, 2735-2740.

Chen, C.Z., Li, L., Lodish, H.F., and Bartel, D.P. (2004). MicroRNAs modulate hematopoietic lineage differentiation. Science 303, 83-86.

Chen, T., Li, Z., Jing, T., Zhu, W., Ge, J., Zheng, X., Pan, X., Yan, H., and Zhu, J. (2011a). MicroRNA-146a regulates the maturation process and pro-inflammatory cytokine secretion by targeting CD40L in oxLDL-stimulated dendritic cells. FEBS Lett 585, 567-573.

Chen, T., Li, Z., Tu, J., Zhu, W., Ge, J., Zheng, X., Yang, L., Pan, X., Yan, H., and Zhu, J. (2011b). MicroRNA-29a regulates pro-inflammatory cytokine secretion and scavenger receptor expression by targeting LPL in oxLDL-stimulated dendritic cells. FEBS Lett 585, 657-663.

Chen, T., Yan, H., Li, Z., Jing, T., Zhu, W., Ge, J., Zheng, X., Pan, X., and Zhu, J. (2011c). MicroRNA-155 regulates lipid uptake, adhesion/chemokine marker secretion and SCG2 expression in oxLDL-stimulated dendritic cells/macrophages. Int J Cardiol 147, 446-447.

Cheong, C., Matos, I., Choi, J.H., Dandamudi, D.B., Shrestha, E., Longhi, M.P., Jeffrey, K.L., Anthony, R.M., Kluger, C., Nchinda, G., et al. (2010). Microbial stimulation fully differentiates monocytes to DC-SIGN/CD209(+) dendritic cells for immune T cell areas. Cell 143, 416-429.

Chong, M.M., Rasmussen, J.P., Rudensky, A.Y., and Littman, D.R. (2008). The RNAselll enzyme Drosha is critical in T cells for preventing lethal inflammatory disease. J Exp Med 205, 2005-2017.

den Haan, J.M., Lehar, S.M., and Bevan, M.J. (2000). CD8(+) but not CD8(-) dendritic cells cross-prime cytotoxic $T$ cells in vivo. J Exp Med 192, 1685-1696.

Dominguez, P.M., and Ardavin, C. (2010). Differentiation and function of mouse monocyte-derived dendritic cells in steady state and inflammation. Immunol Rev 234, 90-104.

Du, J., Wang, J., Tan, G., Cai, Z., Zhang, L., Tang, B., and Wang, Z.
(2012). Aberrant elevated microRNA-146a in dendritic cells (DC) induced by human pancreatic cancer cell line BxPC-3-conditioned medium inhibits DC maturation and activation. Med Oncol. (In press)

Dunand-Sauthier, I., Santiago-Raber, M.L., Capponi, L., Vejnar, C.E., Schaad, O., Irla, M., Seguin-Estevez, Q., Descombes, P., Zdobnov, E.M., Acha-Orbea, H., et al. (2011). Silencing of c-Fos expression by microRNA-155 is critical for dendritic cell maturation and function. Blood 117, 4490-4500.

Edelson, B.T., Bradstreet, T.R., Hildner, K., Carrero, J.A., Frederick, K.E., Kc, W., Belizaire, R., Aoshi, T., Schreiber, R.D., Miller, M.J., et al. (2011). CD8alpha(+) dendritic cells are an obligate cellular entry point for productive infection by Listeria monocytogenes. Immunity 35, 236-248.

Edelson, B.T., Kc, W., Juang, R., Kohyama, M., Benoit, L.A., Klekotka, P.A., Moon, C., Albring, J.C., Ise, W., Michael, D.G., et al. (2010). Peripheral CD103+ dendritic cells form a unified subset developmentally related to CD8alpha+ conventional dendritic cells. J Exp Med 207, 823-836.

Edwards, A.D., Diebold, S.S., Slack, E.M., Tomizawa, H., Hemmi, H., Kaisho, T., Akira, S., and Reis e Sousa, C. (2003). Toll-like receptor expression in murine DC subsets: lack of TLR7 expression by CD8 alpha+ DC correlates with unresponsiveness to imidazoquinolines. Eur J Immunol 33, 827-833.

Geijtenbeek, T.B., Kwon, D.S., Torensma, R., van Vliet, S.J., van Duijnhoven, G.C., Middel, J., Cornelissen, I.L., Nottet, H.S., KewalRamani, V.N., Littman, D.R., et al. (2000). DC-SIGN, a dendritic cell-specific HIV-1-binding protein that enhances trans-infection of T cells. Cell 100, 587-597.

Geissmann, F., Manz, M.G., Jung, S., Sieweke, M.H., Merad, M., and Ley, K. (2010). Development of monocytes, macrophages, and dendritic cells. Science 327, 656-661.

Grumont, R., Hochrein, H., O'Keeffe, M., Gugasyan, R., White, C., Caminschi, I., Cook, W., and Gerondakis, S. (2001). c-Rel regulates interleukin 12 p70 expression in CD8(+) dendritic cells by specifically inducing p35 gene transcription. J Exp Med 194, 1021-1032.

Hashimi, S.T., Fulcher, J.A., Chang, M.H., Gov, L., Wang, S., and Lee, B. (2009). MicroRNA profiling identifies miR-34a and miR-21 and their target genes JAG1 and WNT1 in the coordinate regulation of dendritic cell differentiation. Blood 114, 404-414.

Hochrein, H., Shortman, K., Vremec, D., Scott, B., Hertzog, P., and O'Keeffe, M. (2001). Differential production of IL-12, IFN-alpha, and IFN-gamma by mouse dendritic cell subsets. J Immunol 166, 5448-5455.

Hsieh, C.S., Macatonia, S.E., Tripp, C.S., Wolf, S.F., O'Garra, A., and Murphy, K.M. (1993). Development of TH1 CD4+ T cells through IL-12 produced by Listeria-induced macrophages. Science 260 , 547-549.

Inaba, K., Inaba, M., Romani, N., Aya, H., Deguchi, M., Ikehara, S., Muramatsu, S., and Steinman, R.M. (1992). Generation of large numbers of dendritic cells from mouse bone marrow cultures supplemented with granulocyte/macrophage colony-stimulating factor. J Exp Med 176, 1693-1702.

Iyoda, T., Shimoyama, S., Liu, K., Omatsu, Y., Akiyama, Y., Maeda, Y., Takahara, K., Steinman, R.M., and Inaba, K. (2002). The CD8+ dendritic cell subset selectively endocytoses dying cells in 
culture and in vivo. J Exp Med 195, 1289-1302.

Jackson, J.T., Hu, Y., Liu, R., Masson, F., D'Amico, A., Carotta, S., Xin, A., Camilleri, M.J., Mount, A.M., Kallies, A., et al. (2011). Id2 expression delineates differential checkpoints in the genetic program of CD8alpha(+) and CD103(+) dendritic cell lineages. EMBO J 30, 2690-2704.

Johnson, S., Zhan, Y., Sutherland, R.M., Mount, A.M., Bedoui, S., Brady, J.L., Carrington, E.M., Brown, L.E., Belz, G.T., Heath, W.R., et al. (2009). Selected Toll-like receptor ligands and viruses promote helper-independent cytotoxic $T$ cell priming by upregulating CD40L on dendritic cells. Immunity 30, 218-227.

Jurkin, J., Schichl, Y.M., Koeffel, R., Bauer, T., Richter, S., Konradi, S., Gesslbauer, B., and Strobl, H. (2010). miR-146a is differentially expressed by myeloid dendritic cell subsets and desensitizes cells to TLR2-dependent activation. J Immunol 184, 4955-4965.

Kaplan, D.H., Jenison, M.C., Saeland, S., Shlomchik, W.D., and Shlomchik, M.J. (2005). Epidermal langerhans cell-deficient mice develop enhanced contact hypersensitivity. Immunity 23, 611-620.

King, I.L., Kroenke, M.A., and Segal, B.M. (2010). GM-CSFdependent, CD103+ dermal dendritic cells play a critical role in Th effector cell differentiation after subcutaneous immunization. J Exp Med 207, 953-961.

Kuipers, H., Schnorfeil, F.M., and Brocker, T. (2010a). Differentially expressed microRNAs regulate plasmacytoid vs. conventional dendritic cell development. Mol Immunol 48, 333-340.

Kuipers, H., Schnorfeil, F.M., Fehling, H.J., Bartels, H., and Brocker, T. (2010b). Dicer-dependent microRNAs control maturation, function, and maintenance of Langerhans cells in vivo. J Immunol 185, 400-409.

Lanoue, A., Clatworthy, M.R., Smith, P., Green, S., Townsend, M.J., Jolin, H.E., Smith, K.G., Fallon, P.G., and McKenzie, A.N. (2004). SIGN-R1 contributes to protection against lethal pneumococcal infection in mice. J Exp Med 200, 1383-1393.

Leon, B., Lopez-Bravo, M., and Ardavin, C. (2007). Monocyte-derived dendritic cells formed at the infection site control the induction of protective Thelper 1 responses against Leishmania. Immunity 26, 519-531.

Lewis, K.L., Caton, M.L., Bogunovic, M., Greter, M., Grajkowska, L.T., Ng, D., Klinakis, A., Charo, I.F., Jung, S., Gommerman, J.L., et al. (2011). Notch2 receptor signaling controls functional differentiation of dendritic cells in the spleen and intestine. Immunity 35, 780-791.

Liu, X., Zhan, Z., Xu, L., Ma, F., Li, D., Guo, Z., Li, N., and Cao, X. (2010). MicroRNA-148/152 impair innate response and antigen presentation of TLR-triggered dendritic cells by targeting CaMKIlalpha. J Immunol 185, 7244-7251.

Liu, Y., Chen, Q., Song, Y., Lai, L., Wang, J., Yu, H., Cao, X., and Wang, Q. (2011). MicroRNA-98 negatively regulates IL-10 production and endotoxin tolerance in macrophages after LPS stimulation. FEBS Lett 585, 1963-1968.

Lu, C., Huang, X., Zhang, X., Roensch, K., Cao, Q., Nakayama, K.I., Blazar, B.R., Zeng, Y., and Zhou, X. (2011a). miR-221 and miR-155 regulate human dendritic cell development, apoptosis, and IL-12 production through targeting of p27kip1, KPC1, and SoCS-1. Blood 117, 4293-4303.
Lu, L.F., Thai, T.H., Calado, D.P., Chaudhry, A., Kubo, M., Tanaka, K., Loeb, G.B., Lee, H., Yoshimura, A., Rajewsky, K., et al. (2009a). Foxp3-dependent microRNA155 confers competitive fitness to regulatory $T$ cells by targeting SOCS1 protein. Immunity 30, 80-91.

Lu, T.X., Hartner, J., Lim, E.J., Fabry, V., Mingler, M.K., Cole, E.T., Orkin, S.H., Aronow, B.J., and Rothenberg, M.E. (2011b). MicroRNA-21 limits in vivo immune response-mediated activation of the IL-12/IFN-gamma pathway, Th1 polarization, and the severity of delayed-type hypersensitivity. J Immunol 187, 3362-3373.

Lu, T.X., Munitz, A., and Rothenberg, M.E. (2009b). MicroRNA-21 is up-regulated in allergic airway inflammation and regulates IL-12p35 expression. J Immunol 182, 4994-5002.

Ma, F., Liu, X., Li, D., Wang, P., Li, N., Lu, L., and Cao, X. (2010). MicroRNA-466l upregulates IL-10 expression in TLR-triggered macrophages by antagonizing RNA-binding protein tristetraprolinmediated IL-10 mRNA degradation. J Immunol 184, 6053-6059.

Martinez-Nunez, R.T., Louafi, F., Friedmann, P.S., and Sanchez-Elsner, T. (2009). MicroRNA-155 modulates the pathogen binding ability of dendritic cells (DCs) by down-regulation of DC-specific intercellular adhesion molecule-3 grabbing non-integrin (DC-SIGN). J Biol Chem 284, 16334-16342.

Merad, M., Ginhoux, F., and Collin, M. (2008). Origin, homeostasis and function of Langerhans cells and other langerin-expressing dendritic cells. Nat Rev Immunol 8, 935-947.

Montecalvo, A., Larregina, A.T., Shufesky, W.J., Stolz, D.B., Sullivan, M.L., Karlsson, J.M., Baty, C.J., Gibson, G.A., Erdos, G., Wang, Z., et al. (2012). Mechanism of transfer of functional microRNAs between mouse dendritic cells via exosomes. Blood 119, 756-766.

Naik, S.H., Metcalf, D., van Nieuwenhuijze, A., Wicks, I., Wu, L., O'Keeffe, M., and Shortman, K. (2006). Intrasplenic steady-state dendritic cell precursors that are distinct from monocytes. Nat Immunol 7, 663-671.

Nakano, H., Yanagita, M., and Gunn, M.D. (2001). $\mathrm{CD} 11 \mathrm{C}(+) \mathrm{B} 220(+) \mathrm{Gr}-1(+)$ cells in mouse lymph nodes and spleen display characteristics of plasmacytoid dendritic cells. J Exp Med 194, 1171-1178.

Neuenhahn, M., Kerksiek, K.M., Nauerth, M., Suhre, M.H., Schiemann, M., Gebhardt, F.E., Stemberger, C., Panthel, K., Schroder, S., Chakraborty, T., et al. (2006). CD8alpha+ dendritic cells are required for efficient entry of Listeria monocytogenes into the spleen. Immunity 25, 619-630.

O'Connell, R.M., Chaudhuri, A.A., Rao, D.S., and Baltimore, D. (2009). Inositol phosphatase SHIP1 is a primary target of miR-155. Proc Natl Acad Sci U S A 106, 7113-7118.

O'Connell, R.M., Kahn, D., Gibson, W.S., Round, J.L., Scholz, R.L., Chaudhuri, A.A., Kahn, M.E., Rao, D.S., and Baltimore, D. (2010). MicroRNA-155 promotes autoimmune inflammation by enhancing inflammatory T cell development. Immunity 33, 607-619.

O'Keeffe, M., Hochrein, H., Vremec, D., Caminschi, I., Miller, J.L., Anders, E.M., Wu, L., Lahoud, M.H., Henri, S., Scott, B., et al. (2002). Mouse plasmacytoid cells: long-lived cells, heterogeneous in surface phenotype and function, that differentiate into CD8(+) dendritic cells only after microbial stimulus. J Exp Med 196, 
1307-1319.

Pauley, K.M., Stewart, C.M., Gauna, A.E., Dupre, L.C., Kuklani, R., Chan, A.L., Pauley, B.A., Reeves, W.H., Chan, E.K., and Cha, S. (2011). Altered miR-146a expression in Sjogren's syndrome and its functional role in innate immunity. Eur $\mathrm{J}$ Immunol 41, 2029-2039.

Pegtel, D.M., Cosmopoulos, K., Thorley-Lawson, D.A., van Eijndhoven, M.A., Hopmans, E.S., Lindenberg, J.L., de Gruijl, T.D., Wurdinger, T., and Middeldorp, J.M. (2010). Functional delivery of viral miRNAs via exosomes. Proc Natl Acad Sci U S A 107, 6328-6333.

Poulin, L.F., Henri, S., de Bovis, B., Devilard, E., Kissenpfennig, A., and Malissen, B. (2007). The dermis contains langerin+ dendritic cells that develop and function independently of epidermal Langerhans cells. J Exp Med 204, 3119-3131.

Reid, C.D., Stackpoole, A., Meager, A., and Tikerpae, J. (1992). Interactions of tumor necrosis factor with granulocyte-macrophage colony-stimulating factor and other cytokines in the regulation of dendritic cell growth in vitro from early bipotent CD34+ progenitors in human bone marrow. J Immunol 149, 2681-2688.

Rodriguez, A., Vigorito, E., Clare, S., Warren, M.V., Couttet, P., Soond, D.R., van Dongen, S., Grocock, R.J., Das, P.P., Miska, E.A., et al. (2007). Requirement of bic/microRNA-155 for normal immune function. Science 316, 608-611.

Santiago-Schwarz, F., Divaris, N., Kay, C., and Carsons, S.E. (1993). Mechanisms of tumor necrosis factor-granulocyte-macrophage colony-stimulating factor-induced dendritic cell development. Blood 82, 3019-3028.

Sathe, P., and Wu, L. (2011). The network of cytokines, receptors and transcription factors governing the development of dendritic cell subsets. Protein Cell 2, 620-630.

Serbina, N.V., and Pamer, E.G. (2006). Monocyte emigration from bone marrow during bacterial infection requires signals mediated by chemokine receptor CCR2. Nat Immunol 7, 311-317.

Serbina, N.V., Salazar-Mather, T.P., Biron, C.A., Kuziel, W.A., and Pamer, E.G. (2003). TNF/iNOS-producing dendritic cells mediate innate immune defense against bacterial infection. Immunity 19, 59-70.

Sharma, A., Kumar, M., Aich, J., Hariharan, M., Brahmachari, S.K., Agrawal, A., and Ghosh, B. (2009). Posttranscriptional regulation of interleukin-10 expression by hsa-miR-106a. Proc Natl Acad Sci U S A 106, 5761-5766.

Shklovskaya, E., O'Sullivan, B.J., Ng, L.G., Roediger, B., Thomas, R., Weninger, W., and Fazekas de St Groth, B. (2011). Langerhans cells are precommitted to immune tolerance induction. Proc Natl Acad Sci U S A 108, 18049-18054.

Shortman, K., and Naik, S.H. (2007). Steady-state and inflammatory dendritic-cell development. Nat Rev Immunol 7, 19-30.

Steinman, R.M., and Cohn, Z.A. (1973). Identification of a novel cell type in peripheral lymphoid organs of mice. I. Morphology, quantitation, tissue distribution. J Exp Med 137, 1142-1162.

Stockinger, B., and Veldhoen, M. (2007). Differentiation and function of Th17 T cells. Curr Opin Immunol 19, 281-286.

Sun, Y., Varambally, S., Maher, C.A., Cao, Q., Chockley, P., Toubai, T., Malter, C., Nieves, E., Tawara, I., Wang, Y., et al. (2011). Targeting of microRNA-142-3p in dendritic cells regulates endotoxin-induced mortality. Blood 117, 6172-6183.
Tserel, L., Runnel, T., Kisand, K., Pihlap, M., Bakhoff, L., Kolde, R., Peterson, H., Vilo, J., Peterson, P., and Rebane, A. (2011). MicroRNA expression profiles of human blood monocyte-derived dendritic cells and macrophages reveal miR-511 as putative positive regulator of Toll-like receptor 4. J Biol Chem 286, 26487-26495.

Turner, M.L., Schnorfeil, F.M., and Brocker, T. (2011). MicroRNAs regulate dendritic cell differentiation and function. J Immunol 187, 3911-3917.

Valadi, H., Ekstrom, K., Bossios, A., Sjostrand, M., Lee, J.J., and Lotvall, J.O. (2007). Exosome-mediated transfer of mRNAs and microRNAs is a novel mechanism of genetic exchange between cells. Nat Cell Biol 9, 654-659.

Varol, C., Vallon-Eberhard, A., Elinav, E., Aychek, T., Shapira, Y., Luche, H., Fehling, H.J., Hardt, W.D., Shakhar, G., and Jung, S. (2009). Intestinal lamina propria dendritic cell subsets have different origin and functions. Immunity 31, 502-512.

Wakim, L.M., Waithman, J., van Rooijen, N., Heath, W.R., and Carbone, F.R. (2008). Dendritic cell-induced memory T cell activation in nonlymphoid tissues. Science 319, 198-202.

Wen, H., Dou, Y., Hogaboam, C.M., and Kunkel, S.L. (2008). Epigenetic regulation of dendritic cell-derived interleukin-12 facilitates immunosuppression after a severe innate immune response. Blood 111, 1797-1804.

Xiao, C., Calado, D.P., Galler, G., Thai, T.H., Patterson, H.C., Wang, J., Rajewsky, N., Bender, T.P., and Rajewsky, K. (2007). MiR-150 controls $\mathrm{B}$ cell differentiation by targeting the transcription factor c-Myb. Cell 131, 146-159.

Xiao, C., and Rajewsky, K. (2009). MicroRNA control in the immune system: basic principles. Cell 136, 26-36.

Xu, Y., Zhan, Y., Lew, A.M., Naik, S.H., and Kershaw, M.H. (2007). Differential development of murine dendritic cells by GM-CSF versus Flt3 ligand has implications for inflammation and trafficking. J Immunol 179, 7577-7584.

Xue, X., Feng, T., Yao, S., Wolf, K.J., Liu, C.G., Liu, X., Elson, C.O., and Cong, Y. (2011). Microbiota downregulates dendritic cell expression of miR-10a, which targets IL-12/IL-23p40. J Immunol 187, 5879-5886.

Zhan, Y., Carrington, E.M., van Nieuwenhuijze, A., Bedoui, S., Seah, S., Xu, Y., Wang, N., Mintern, J.D., Villadangos, J.A., Wicks, I.P., et al. (2011). GM-CSF increases cross presentation and CD103 expression by mouse CD8(+) spleen dendritic cells. Eur J Immunol. 41, 2585-2595.

Zhan, Y., Xu, Y., and Lew, A.M. (2012). The regulation of the development and function of dendritic cell subsets by GM-CSF: More than a hematopoietic growth factor. Mol Immunol 52, 30-37.

Zhan, Y., Xu, Y., Seah, S., Brady, J.L., Carrington, E.M., Cheers, C., Croker, B.A., Wu, L., Villadangos, J.A., and Lew, A.M. (2010). Resident and monocyte-derived dendritic cells become dominant IL-12 producers under different conditions and signaling pathways. J Immunol 185, 2125-2133.

Zhang, M., Liu, F., Jia, H., Zhang, Q., Yin, L., Liu, W., Li, H., Yu, B., and $\mathrm{Wu}$, J. (2011). Inhibition of microRNA let-7i depresses maturation and functional state of dendritic cells in response to lipopolysaccharide stimulation via targeting suppressor of cytokine signaling 1. J Immunol 187, 1674-1683.

Zhang, Y., Liu, D., Chen, X., Li, J., Li, L., Bian, Z., Sun, F., Lu, J., Yin, 
Y., Cai, X., et al. (2010). Secreted monocytic miR-150 enhances targeted endothelial cell migration. Mol Cell 39, 133-144.

Zheng, J., Jiang, H.Y., Li, J., Tang, H.C., Zhang, X.M., Wang, X.R., Du, J.T., Li, H.B., and Xu, G. (2012). MicroRNA-23b promotes tolerogenic properties of dendritic cells in vitro through inhibiting
Notch1/NF-kappaB signalling pathways. Allergy 67, 362-370.

Zhou, H., Huang, X., Cui, H., Luo, X., Tang, Y., Chen, S., Wu, L., and Shen, N. (2010). miR-155 and its star-form partner miR-155* cooperatively regulate type I interferon production by human plasmacytoid dendritic cells. Blood 116, 5885-5894. 